\title{
NEWLY FOUND SEAL OF A BYZANTINE STRATEGOS OF PRESLAV
}

\author{
Nikolay Kanev \\ St. Cyril and St. Methodius University of Veliko Tarnovo, Veliko Tarnovo, Bulgaria
}

\begin{abstract}
The article aims at giving currency in the scholarly circles to a new Byzantine lead seal found in Pliska in 2016. This lead bulla is $2,5 \mathrm{~mm}$ thick, it has a diameter of $22 \mathrm{~mm}$ and is preserved in a very good condition. The stamp is of good quality but unfortunately, it has not been well centred and because of this part of the impression and the legend have remained outside the lead core (Fig.). However, the seal is in a sufficiently good shape and its impression is clear enough to allow to ascertain with certainty that it is a new parallel copy of an already known lead seal of a Byzantine stratēgos of which eight copies have been found and published so far. Seven of these copies come from Preslav and one has been found in the vicinity of Silistra.

It is situated on the obverse of this lead bulla, an image of a blossoming doubly intersected patriarchal cross

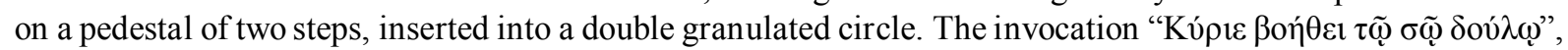
of which the letters R. H $\Theta I T \omega C \omega$ have been preserved, is written in the form of a circle round the image.

On the reverse of the lead seal, clearly enough can be seen the first four lines of the five-line written inscription: $\overline{I T} R \cdot A \cdot|. . A \Theta \cdot K \in| . . P A T H|. . . \in P C| \ldots$

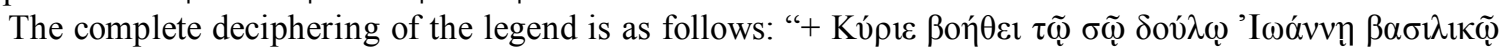

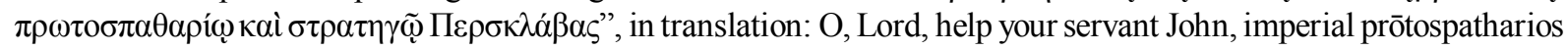
and stratēgos of Persklava (i.e. Preslav).

The seal is dated back to the first quarter of the $11^{\text {th }}$ century.

Key words: lead seal, John, stratēgos, Preslav (Persklava), imperial prōtospatharios, Byzantium.

Citation. Kanev N. Newly Found Seal of a Byzantine Strategos of Preslav. Vestnik Volgogradskogo gosudarstvennogo universiteta. Seriya 4, Istoriya. Regionovedenie. Mezhdunarodnye otnosheniya [Science Journal of Volgograd State University. History. Area Studies. International Relations], 2017, vol. 22, no. 5, pp. 112-115 (in Russian). DOI: https://doi.org/10.15688/jvolsu4.2017.5.10
\end{abstract}

УДК 93

ББК 63.2
Дата поступления статьи: 28.08.2017

Дата принятия статьи: 27.09.2017

\section{НОВАЯ НАХОДКА ПЕЧАТИ ВИЗАНТИЙСКОГО СТРАТИГА ГОРОДА ПРЕСЛАВ}

\author{
Николай Кънев \\ Великотырновский университет им. Святых Кирилла и Мефодия, г. Велико Тырново, Болгария
}

\begin{abstract}
Аннотация. Статья имеет целью ввести в научное обращение в русские научные круги новую византийскую свинцовую печать, найденную в 2016 г. в древней болгарской столице Плиска. Печать в очень хорошем состоянии и, несмотря на то что оттиск плохо центрирован, отчего часть изображения и легенда остались за пределами свинцового кружка, она достаточно четкая и позволяет установить, что это новый, параллельный экземпляр уже известного моливдовула византийского стратига города Преслав, а именно императорского протоспафария Иоанна. Датировка печати относится к первой четверти XI века.

Ключевые слова: моливдовул, Иоанн, стратиг, Преслав, императорский протоспафарий, Византия.

Цитирование. Кьнев Н. Новая находка печати византийского стратига города Преслав // Вестник Волгоградского государственного университета. Серия 4, История. Регионоведение. Международные отноше(2)
\end{abstract}


В 2016 г. во время регулярных археологических раскопок в юго-западном секторе Внутреннего города Плиски была найдена византийская свинцовая печать, предоставленная автору настоящей статьи для прочтения, датирования и опубликования ${ }^{1}$.

Моливдовул диаметром 22 мм, толщиной 2,5 мм и весом 7,41 г и в хорошей сохранности. Оттиск качественный, но, к сожалению, плохо центрирован, отчего часть изображения и часть легенда остались за пределами свинцового кружка (см. рисунок). Печать, однако, в достаточно хорошем состоянии и достаточно четкая, что позволяет с уверенностью установить, что это новый, параллельный экземпляр уже известного моливдовула византийского стратига, от которого до сих пор найдены и опубликованы восемь экземпляров, семь из которых найдены в Преславе и один - в районе Силистры (см.: [1, с. 146-147, № 291297; 4, № 63.3h; 5, p. 469-470, № 1397-1403A]).

Аверс. Очень качественно выполненное орнаментированное изображение расцветшегос двумя перекладинами патриаршего креста на постаменте из двух ступенек, вписанного в двойной зернистый круг. В кругу, вокруг изображения, частично сохранившаяся круговая надпись:

..R.HOITWCW...

$[+\mathrm{K}(\hat{\rho} \rho \mathrm{l}) \varepsilon] \beta[\mathrm{o}] \eta \dot{\theta} \theta(\varepsilon) \iota \tau \tilde{\varphi} \sigma \tilde{\varphi}[\delta o v ́ \lambda \omega]$.

В отличие от этих букв, которые расположены сверху над изображением (то есть өІT(JC()) и которые хорошо видны, рядом с ними лишь при внимательном рассмотрении различаются следы только $\mathrm{R}$ и $\mathrm{H}$, так как они почти полностью стерты. Сохранившиеся бук-

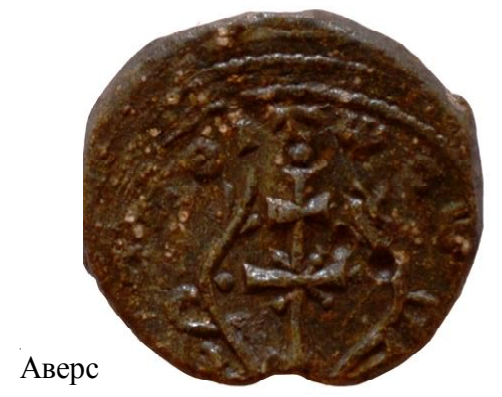

вы и их расположение вокруг изображения вполне достаточны, чтобы установить, что речь идет о написании $K \in R O H \Theta I T \omega C \omega \Delta \succ \wedge s$, которое фигурирует на лицевой стороне на известных параллелях этого моливдовула.

Реверс. Пятистрочная надпись, от которой видны первые четыре строчки:

.ITUR'A $|. . A \Theta \cdot K \in| . . P A T H|\ldots \in P C| \ldots$

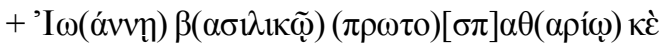
$[\sigma \tau] \rho \alpha \tau \eta[\gamma \tilde{\omega}][\Pi] \varepsilon \rho \sigma[\kappa \lambda \alpha \dot{\alpha} \beta \alpha](\varsigma)$

Начало строчек отрезано из-за плохого центрирования моливдовула, по той же причине отсутствует и последняя, пятая, строчка. На первой строчке нет первого знака, а именно крестика, с которого традиционно начинается написание легенды на каждой из сторон византийских печатей. На второй и третьей строчке отрезаны первые две буквы, а на четвертой вероятно, даже первые три буквы. Несмотря на отсутствие букв, однако, остальные буквы хорошо сохранились и разборчивы, что позволяет беспроблемное прочтение выписанной на реверсе части легенды, а также и констатацию указанного выше факта, а именно, что опубликованный здесь сфрагистический памятник имеет уже известные параллели.

Целостное развертывание легенды следующее:

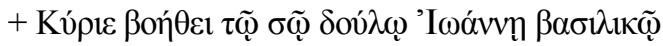

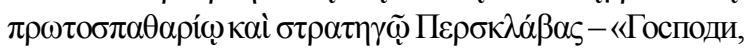
помоги рабу своему Иоанну, императорскому протоспафарию и стратигу Персклавы» (то есть Преслава).

Датировка печати входит в рамки хронологического отрезка, охватывающего последние три десятилетия $\mathrm{X}$ и первую четверть

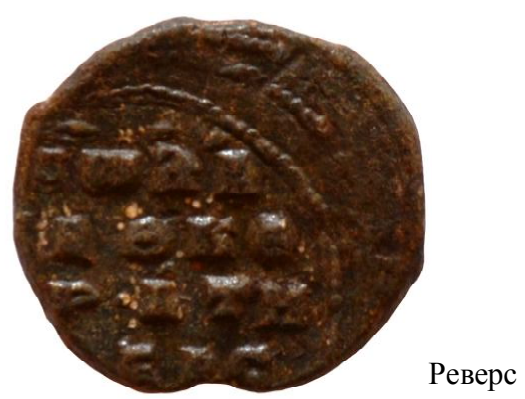

Лицевая и оборотная сторона моливдовула Иоанна, императорского протоспафария и стратига Персклавы, найденного в Плиске

Head and back sides of the lead seal of John, imperial prōtospatharios and strategos of Preslav, found in Pliska 


\section{ВИЗАНТИЙСКАЯ СФРАГИСТИКА}

XI века. С очень высокой степенью уверенности, однако, эту датировку можно отнести скорее всего к первой четверти XI века. Основанием для датирования после повторного восстановления византийской власти над северо-восточными болгарскими землями послужил факт, что на своей печати императорский протоспафарий Иоанн указывает, что он стратиг бывшей болгарской столицы Преслав, используя воспринятый византийцами очень близкий к оригинальному фонетический вариант ее названия - Персклава ${ }^{2}$. В предыдущий период византийской власти в этой части Болгарии - в 70-е и 80-е гг. Х в. - Велики Преслав, как хорошо известно, официально назывался Иоаннополь, и именно это название использовали на своих моливдовулах византийские стратиги, резидирующие в Преславе, чтобы указать свое служебное положение стратига Иоаннополя. Несмотря на то, что в целом иконографические и палеографические особенности печати как будто более характерны для десятого, чем для одиннадцатого столетия, именно наличие названия Персклава, а не Иоаннополь, в сочетании с немалым количеством известных экземпляров этой печати, совсем очевидно исключает предположение о датировке до рубежа X и XI веков.

С опубликованным здесь моливдовулом печати Иоанна, императорского протосnафария и стратига Персклавы насчитывают девять штук, а к ареалу местонахождения уже прибавляется и Плиска. Нельзя не заметить, что этот ареал остается сравнительно ограниченным в территориальном отношении (Преслав, Плиска, Дристра), а это говорит о переписке, связанной в целом с самыми прямыми, обычными ежедневными служебными обязанностями Иоанна как стратига Преслава, а это, со своей стороны, хотя и с рядом оговорок, может быть воспринято и как своего рода косвенный показатель того, что время его правления в византийской административной единице с центром в бывшей болгарской столице совпало с относительно спокойным и мирным периодом в регионе.

\section{ПРИМЕЧАНИЯ}

1 Пользуюсь случаем поблагодарить коллегу Христину Стоянову - руководителя раскопок, которая предоставила мне печать для прочтения, датирования и опубликования, за информацию о ее местонахождении и археологической среде. Находка найдена в секторе, в котором исследуется большой архитектурный комплекс, существовавший во второй половине X в. и в начале XI в., в котором есть следы и более позднего периода - приблизительно до середины XI века. Об истории и результатах раскопок в секторе см.: [2, с. 644-646; 3, c. 585-588].

${ }^{2}$ В своих публикациях известных до сих пор экземпляров печати Иоанна, императорского протоспафария и стратига Персклавы, найденных в Преславе и Силистре, проф. И. Йорданов комментирует две самые вероятные возможности ее датировки: 1) в интервале апрель - август 971 г., то есть до переименования Преслава в Иоаннополь; и, соответственно, - 2) после повторного завоевания Преслава византийцами в 1000 г., - отдавая предпочтение первой из этих двух возможностей, связывая ее с активностью «...в начальный период функционирования учреждения, когда там находился некий надведомственный орган, стоящий над пишущими в город стратигами - наместник императора, управляющий новозавоеванными землями» $[1$, c. 147]. Все-таки количество уже известных печатей преславского стратига Иоанна достаточно велико, а кроме того, они почти все найдены в самом Преславе, что является достаточным основанием усомниться, насколько это связано с его кратковременным (эвентуально четырехмесячным) управлением поздней весной и летом 971 г., и это как будто делает более логичной и допустимой вторую гипотезу, высказанную проф. И. Йордановым.

\section{СПИСОК ЛИТЕРАТУРЫ}

1. Йорданов, И. Печатите от стратегията Преслав (971-1088) / И. Йорданов. - София : УИ «Св. Климент Охридски», 1993. - 266 с.

2. Стоянова, Х. Сграда в Югозападния сектор на Вътрешния град на Плиска / Х. Стоянова // Археологически открития и разкопки през 2015. - София : [б. и.], 2016. - С. 644-646.

3. Стоянова, Х. Сграда в Югозападния сектор на Вътрешния град на Плиска / Х. Стоянова // Археологически открития и разкопки през 2014. - София : [б. и.], 2015. - С. 585-588.

4. Jordanov, I. Corpus of Byzantine seals from Bulgaria. Vol. II: Seals with Family Names / I. Jordanov. Sofia : Bulgarian Academy of Sciences; Archaeological Institute with Museum, 2006. - 546, [6] p.

5. Jordanov, I. Corpus of Byzantine seals from Bulgaria. Vol. III, Pt. 1-2 / I. Jordanov. - Sofia : Bulgarian Academy of Sciences : Archaeological Institute with Museum, 2009. - $1274 \mathrm{p}$. 


\section{REFERENCES}

1. Yordanov I. Pechatite ot strategiyata Preslav (971-1088) [The Seals from the Strategy of Preslav (971-1088)]. Sofia, UI “Sv. Kliment Okhridski”, 1993. $266 \mathrm{p}$.

2. Stoyanova Kh. Sgrada v Yugozapadniya sektor na Vtreshniya grad na Pliska [Building in the Southwest Sector of the Inner City of Pliska]. Arkheologicheski otkritiya i razkopki prez 2015 [Archaeological Discoveries and Excavations for 2015]. Sofia, 2016, pp. 644-646.
3. Stoyanova Kh. Sgrada v Yugozapadniya sektor na Vtreshniya grad na Pliska [Building in the Southwest Sector of the Inner City of Pliska]. Arkheologicheski otkritiya $i$ razkopki prez 2014 [Archaeological Discoveries and Excavations for 2014]. Sofia, 2015, pp. 585-588.

4. Jordanov I. Corpus of Byzantine seals from Bulgaria. Vol. II: Seals with Family Names. Sofia, Bulgarian Academy of Sciences; Archaeological Institute with Museum, 2006. 546, [6] p.

5. Jordanov I. Corpus of Byzantine seals from Bulgaria. Vol. III, Parts 1-2. Sofia, Bulgarian Academy of Sciences; Archaeological Institute with Museum, 2009. 1274 p.

\section{Information about the Author}

Nikolay Kanev, PhD, Associate Professor, Vice-Dean of the Faculty of History, St. Cyril and St. Methodius University of Veliko Tarnovo, Theodosiy Tarnovski St., 2, 5003 Veliko Tarnovo, Bulgaria, kan-nikolay@yandex.ru,http://orcid.org/0000-0003-0570-8078

\section{Информация об авторе}

Николай Кънев, $\mathrm{PhD}$, доцент, продекан исторического факультета, Великотырновский университет им. Святых Кирилла и Мефодия, ул. им. Феодосия Тырновского, 2, 5003 г. Велико Тырново, Болгария, kan-nikolay@yandex.ru, http://orcid.org/0000-0003-0570-8078 